\title{
Gerhard Domagk (1895-1964) and the Origin of Anti- Bacterial Therapy
}

\section{Ronald P. Rubin*}

Department of Pharmacology \& Toxicology, Jacobs School of Medicine \& Biomedical Sciences, University at Buffalo; State University of New York, Buffalo, New York 14214 USA

${ }^{\star}$ Correspondence to: Ronald P. Rubin, Department of Pharmacology \& Toxicology, Jacobs School of Medicine \& Biomedical Sciences, University at Buffalo; State University of New York, Buffalo, New York 14214 USA; E-mail: rprubin@buffalo.edu

Received: February 20, 2018; Accepted: March 12, 2018; Published: March 16, 2018;

\begin{abstract}
This article presents the story of Gerhard Domagk, who was responsible for developing Prontosil, the first effective antibacterial agent. Although penicillin was serendipitously discovered by Alexander Fleming before Prontosil, because of expert chemical support, the forerunner of the sulfonamides was the first antibiotic produced commercially and patented.

Even though his work created the age of anti-bacterial therapy, in my view Domagk did not receive the acclaim he deserved. This essay examines the circumstances surrounding Domagk's work, as well as focusing on the other individuals involved in the project who ultimately contributed to its success. The paper also explains how biomedical scientists and chemists integrated their respective expertise to achieve their respective goals. Prior to the work of Domagk, the concept that a bacterial infection could be cured by the systemic administration of a chemical substance was thought by most clinicians to be unrealistic and even foolhardy

Although Gerhard Domagk was awarded the Nobel Prize in 1939, in my view, the scientific community tends to view him as a marginal figure, as compared to Alexander Fleming and Selman Waksman, the discoverer of streptomycin. Domagk not only ushered in the new era of chemotherapy, but he set the landscape by demonstrating to other investigators that infection could be cured. Because there has been no greater advancement in clinical medicine than the advent of anti-bacterial therapy, Domagk's monumental contributions to the welfare of mankind should continue to be revisited and celebrated with the highest accolades.
\end{abstract}

Keywords: Gerhard Domagk; Heinrich Horlein; Prontosil; Anti-bacterial therapy; Sulfanilamide; Bayer; Fritz Mietzsch; Josef Klarer; Pasteur Institute

\section{Background}

The early development of antibacterial agents was predicated upon Paul Ehrlich's germ theory [1] (Figure 1), which postulated that infectious diseases were caused by bacteria, and that an infection could be cured if a given drug was selectively taken up by invading microorganisms. But proof of this theory would have to await the ability to isolate bacteria in culture.

In the early 1900's Ehrlich made further advances in chemotherapy when he introduced arsenicals to cause the reduction of syphilis by $50 \%$. However, results with various metals, such as gold salts and antimony, proved to be inconsistent. Ehrlich misguidedly continued to concentrate on the possible effects of chemical compounds on microorganisms in test tubes or on culture media, rather than in animals or humans. Nevertheless, the pioneering work of Ehrlich would provide Gerhard Domagk with the motivation and commitment to eradicate invading bacteria in laboratory animals and humans by the discovery of Prontosil [2].



Figure 1. Paul Ehrlich. Taken from Wikiwand. www.wikiwand. com/gl/Paul_Ehrlich. 


\section{Early years}

Gerhard Domagk was the son of a teacher and assistant Headmaster of a school in Germany [3] (Figure 2). Educated in schools that emphasized science, Domagk made an early decision to become a physician. He began a course in Medicine at the University of Kiel in 1914; but was forced to interrupt his studies because of the outbreak of the first world war. After serving as a medical corpsman, he completed his medical degree in 1921. Wounded during the war, Domagk was exposed first hand to the limits of medicine to treat the wounded by utilizing the antiseptic properties of chlorine water and carbonic acid. At the time, this treatment did not eradicate fatal diseases such as gangrene and usually ended in the amputation of limbs. Domagk observed how easily wounded soldiers contracted gas gangrene, which spawned his enduring interest in curing these infections [4].

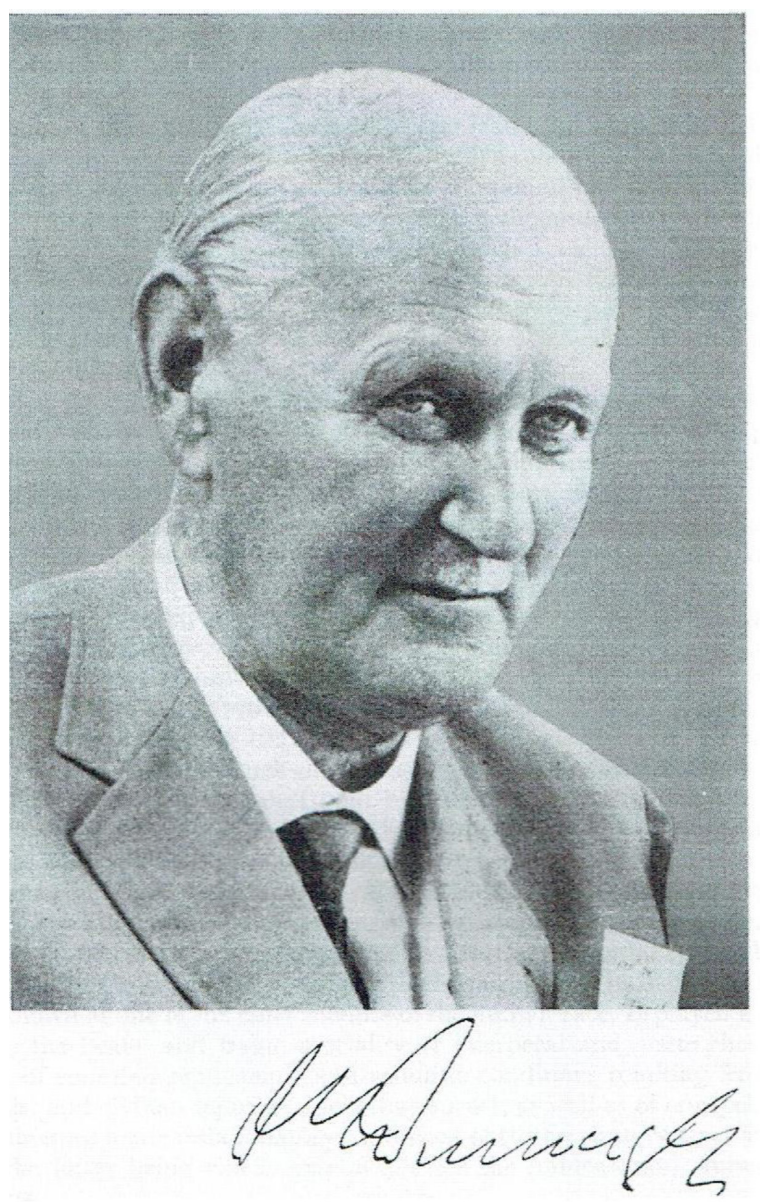

Figure 2. Gerhard Domagk (taken from L. Colebrook. Biogr. Mem. Royal Soc. 1964; 10: pg. 38)

http://www.jstor.org/stable/769310.

As a disciple of Paul Ehrlich, a giant of nineteenth century science, Domagk viewed that the action of a drug was attributed to its effect on the immune system [5]. Toward this end, he learned how to inoculate animals, dissect their organs, and analyze tissues under the microscope. After serving for short a period of time in the laboratory of Professor Hoppe Seyler and then in 1923 in the Pathological Institute at Greifswald, Domagk decided to pursue a research career in experimental pathology and incorporate physiology and chemistry in his work [6]. He assumed a faculty position in the Department of Pathology at the University of Munster.

However in 1927, faced with an inadequate source of funds and the lack of a clear path to career advancement, Domagk was recruited by the pharmaceutical division of I.G. Farbenindustrie, a giant conglomerate composed of leading German chemical companies that included Bayer and Hoechst. The person who hired Domagk was Heinrich Horlein, who had read Domagk's articles on the immune system and was impressed by his ideas about bacteria and the infectious process. Horlein, who came to Bayer in 1909, was eventually put in charge of chemical, bacteriological, and pharmaceutical research at Bayer's Elberfeld-Wuppertal facility [7]. (Figure 3).



Figure 3. Philipp Heinrich Horlein- 1953. (Taken from Wikipedia; 25 Nov-2017.)

Horlein, like Domagk, was an admirer of Paul Ehrlich and was responsible for the discovery of Luminal, an anti-epileptic. Although the scientific world had become resigned to the idea that magic bullets involving synthetic agents were not a realistic goal, Horlein proposed to utilize dyes to study infectious diseases and develop agents that would eradicate invading microorganisms. To carry out this project, he recruited Domagk.

\section{The early development of sulfonamides}

The synthesis of sulfanilamide was first reported in 1909 by a chemistry student named Paul Gelmo at the University of Vienna in his thesis on aniline dyes [8]. However, no mention was made of its potential usefulness as a medical tool. Discovery of its potential 
therapeutic value came in 1909 when Hoerlein and co-workers at I.G. Farben synthesized the first azo dyes [9] containing sulfonamides and noted them to be particularly effective in forming a firm combination with proteins of wool and silk. At the time, Farben was involved in investigating dyes for textile purposes. Although Horlein patented sulfonamides in 1909 [10], he never considered the possibility that the compound could serve as an antibacterial agent. Prontalbin thus became the first version of sulfanilamide produced by Bayer without the company realizing its potential as a clinically effective agent.

The second synthesis of sulfanilamide came in 1915 by Michael Heidelberger, a highly regarded immunologist and winner of the Lasker Award for his work on pneumococcal polysaccharides. He had read about the discovery of sulfanilamide by Gelmo and thought that it may have some antibacterial activity against streptococcus and pneumococcal infections. In 1915, working at Rockefeller University with a chemist named Walter Jacobs, Heidelberger synthesized sulfanilamide and found that bacteria were not eradicated by sulfanilamide in vitro. Even though Heidelberger and Jacobs went on to convert sulfanilamide into a substance which was toxic to infected mice, this investigation was terminated because the authors were unable to envision that a compound with a structure as simple sulfanilamide would be effective in combatting infection. As a result, the development of sulfa drugs was delayed for twenty years and the opportunity to save thousands of lives was temporarily lost. Years later, Heidelberger expressed his profound regrets about not following up on his initial work with sulfanilamide [11].

\section{Development of Prontosil}

During the first half of the $20^{\text {th }}$ century, IG Farben was the largest chemical and pharmaceutical company in the world. Although only 32, Gerhard Domagk was appointed director of research in Experimental Pathology and Bacteriology by Heinrich Horlein [12]. Domagk's task was to establish a renaissance in pharmacotherapy by investigating potential anti-bacterial properties of azo dyes. Domagk had generous financial resources, expanded facilities and expert chemists who were able to synthesize a large number of compounds. He would spend the remainder of his career there.

Paul Ehrlich had used synthetic dyes to stain specific molecules to discover the organic arsenical Salvarsan for the treatment of syphilis; this discovery was followed a few years later by his development of anti-malarials. However, the most life-threatening infections, including streptococcal septicemia, meningitis, and tuberculosis, still remained untreatable by pharmacotherapy In 1932, while searching for a way to combat bacterial infections by chemical means, Domagk by chance discovered a surface-active compound which was marketed under the trade name of Zephiro [13]. This discovery provided him with encouragement to undertake his investigations on azo dyes.

A major hurdle to the success of Domagk's undertaking was to find a suitable test for antibacterial activity. He placed emphasis on testing drugs in living systems, even if they failed to be effective $n$ bacterial cultures in vitro. In forging a strategy, he developed a unique test for screening the survival of mice that had been inoculated with Streptococcus pyogenes. The enhanced virulence of this strain of streptococcus convinced Domagk that the assay would identify only the most effective agents. After screening gold compounds and acridine dyes, Domagk and his team began to obtain more positive results with dyes that were derivatives of sulfonamide containing the sulfa group p-position relative to nitrogen.

Encouraged by the confident and determined approach employed by Domagk, Josef Klarer and Fritz Mietzsch began synthesizing sulfonamide-containing dyes for Domagk to test. The general methodology employed to systematically synthesize and screen a large number of chemically related compounds was similar to that employed by Paul Ehrlich to produce Salvarsan.

The breakthrough came in the mid 1930's after a laborious process that took several years. One of these compounds (KL 695), though inactive in vitro, was found to possess weak activity in mice infected with streptococcus. Buoyed by this minor success, Klarer and Mietzsch continued to synthesize azo compounds and eventually produced $\mathrm{KL}$ 730, which was named Prontosil rubrum (sulfonamidochrysoidine). This compound had a remarkable antibacterial action in mice and a relatively broad effect against gram positive cocci; however, it was ineffective against enterobacteria. Domagk and his team also found that although Prontosil was effective against streptococcal infections in laboratory mice even at low doses, it had no effect in the test tube against microorganisms.

IG Farben applied for a patent in 1932 with the chemists Josef Klarer and Fritz Mietzsch as inventors, covering Prontosil and several other azo dyes. Its new trade name was Streptozon. Ironically, this compound had originally been developed as an industrial dye for wool and leather [14]. It is of interest to note that Klarer and Mietzsch received money for the synthesis of Prontosil, while Domagk, although subsequently being afforded the honor of its discovery, did not.

After Domagk successfully treated rabbits infected with $H$. streptococcus, I.G. Farben began to distribute the drug to physicians. However, Domagk knew that the drug might have a different effect on a bacterial infection in humans; and he began collaborating with a local hospital to test prontosil in humans. By the summer of 1933, Streptozon was demonstrated to be effective and safe in both animal experiments and in a relatively few patients. Although the results were initially received with some skepticism by the medical community, the drug was able to treat even the most severe infections, and the death rate from such diseases as cholera, pneumonia, and meningitis fell sharply.

Although Domagk's work provided the groundwork for the explosive developments in the field of pharmacotherapy that ensued, he was a man dedicated to thoroughness. He was not convinced that Prontosil would be effective in humans until February 1935 when the drug was successfully administered to his four year-old daughter, who had developed septicemia after pricking her finger with a needle [15]. Even then, Domagk waited until clinical reports verified the effectiveness of the drug at a local hospital and Dusseldorf University Hospital, and finally reached the market.

Domagk published his laboratory and clinical findings in February 1935 in the Deutsche Medizinische Wochenschrift, the then preeminent 
medical journal in Germany [16]. These two papers can be described as paradigmatic. Domagk authored a number of additional articles to keep his name in the limelight much to the dismay of Klarer and Mietzsch, who felt that they deserved more credit for the discovery. In any case, French scientists would render the new miracle drug obsolete.

A patent on the drug was granted to Bayer early in 1935, a few months after the French patent. Although the results were first received with some skepticism by the medical community, the findings were quickly reproduced in a British hospital where Prontosil was shown to cure puerperal fever, a now virtually non-existent infection associated with childbirth. Later that year, Prontosil received further recognition when the son of United Staes President Franklin Roosevelt was successfully treated for a severe streptococcal infection. After that, Horlein orchestrated tests of Prontosil rubrum throughout Europe, and after it was patented in 1936, Prontosil began to be widely employed on the European continent [17].

In 1935, Alexander Weech (1895-1977), a pediatrician working at Columbia University, treated the first patient in the United States with prontosil [18]. After translating and reading the publications of Domagk, Weech obtained a supply of the drug from a pharmaceutical company and successfully treated a young girl with a severe streptococcal infection, who happened to be the daughter of a colleague [19].

However, the quantitative metabolic and toxicological studies carried out at John Hopkins by Perrin Long and Eleanor Bliss in 1936 did more than any other center in the United States to elucidate how sulfanilamide worked in both animals and humans [20]. They confirmed that para-aminobenzene-sulfonamide was the effective moiety of the prontosil molecule and that it exerted a bacteriostatic rather than a bacteriocidal effect. By the early 1940's the American companies were producing vast quantities of the drug. It should be emphasized that although penicillin is often credited for being the first antibiotic, Prontosil and other sulfa drugs were employed clinically almost ten years before penicillin became available.

Although Domagk was successful by the tedious and large scale testing of numerous compounds, plus the large investment of funds, a decade later there was a radical change in how drug research was done. James Black and then Gertrude Elion and George Hitchings utilized a more efficient method of drug development by employing basic physiologic and pharmacologic principles to formulate a rationale for achieving drug selectivity, rather than by arbitrarily modifying natural products and testing results empirically [21].

\section{The French participation}

Because of the work of Domagk, scientists, no longer fettered by preconceived biases, began to find great interest in this project. While Bayer chemists continued to pursue unsuccessful studies with azo dyes, in late 1935 a group working at the Pasteur Institute in Paris that was led by the highly regarded chemist Ernest Fourneau, and included the future Nobelist Daniel Bovet, became interested in Domagk's discovery. When Heinrich Horlein received a letter from the Pasteur
Institute requesting a sample of the newly discovered drug, he replied positively [22].

The French group staked a claim to the drug when they found that Prontosil was metabolized to sulfanilamide by testing an agent common to all of the previous products, para-amino-phenyl-sulfonamide [23]. In other words, simple sulfanilamide would have been just as effective as the drug produced by Domagk and his chemists! The findings of the French team derailed any hopes that Bayer might have had to derive a prodigious profit from Domagk's work. Sulfanilamide, the active molecule, had been synthesized and patented in 1909, and the patent had expired. Therefore, the agent was available to anyone.

The French manufactured the compound under the name Rubiazol. It was ironical that chemical manufacturing companies had already produced vast amounts of sulfanilamide as an intermediate in the process of dye manufacturing. In addition to finding that the agent was effective in animals, the French group began distributing the drug to French physicians. Being much less expensive and not causing the skin to turn red, sulfanilamide was superior to the compound produced by Bayer.

The principal significance of the work carried out by the French is that it answered the question as to why Prontosil did not kill bacteria grown outside the living body, as well as to why attaching sulfa to dyes produced a pharmacologically active substance. The French scientists not only discovered that sulfanilamide was active both in vivo and in vitro, but that intestinal enzymes converted Prontosil into sulfanilamide. They were thus able to explain why Prontosil was inactive in vitro.

Because Prontosil had first been patented in 1909, the patent had expired by the time the French team made its discovery. Because any firm could produce the drug and market it, a second communication by Domagk soon after described the new chemotherapeutic dye and gave it the name of prontosil-s (neoprontosil) [24]. Bayer then introduced a group of new agents to the market in Germany which was highly successful.

The scientists at the Pasteur Institute acrimoniously accused Bayer and Domagk of having discovered sulfanilamide in the time period between 1932 and 1935, but purposefully delayed publication until they could find a similar drug that they could patent. The French scientists argued that if Bayer and Domagk had made the results public earlier, then countless lives would have been saved. However, Domagk appears never to have tested sulfanilamide and in fact was unaware that sulfanilamide was its active component. More likely, he delayed publication until he was convinced that the drug was safe for clinical use.

While Domagk delayed publication of his findings for three years, the scientists at the Pasteur Institute began producing a number of sulfa-containing compounds and assessed their effects, which were quickly published. Soon after, the French firm, Rhone-Poulenc, manufactured Septazine that was sufficiently different in structure to enable patenting.

In addition, Sir Henry Dale, Great Britain's most renowned pharmacologist, quickly became interested in Prontosil even before 
information about it appeared in the scientific literature [25]. Dale asked for a supply from Horlein and placed it in the hands of Leonard Colebrook (1883-1967) at Queen Charlotte's Hospital in London. At first, Colebrook found minimal effects of the drug in vitro or in mice, but his subsequent tests on puerperal (child bed) fever quickly achieved very positive results and facilitated the acceptance of the new drug [26].

\section{The Aftermath of Prontosil}

By the end of 1936, Prontosil, the German version and Septazine, the French version, were employed wherever streptococcal infections were rampant. The prontosil line was replete with a large number of trade name variations that flooded the market. Sulfanilamide was officially adopted as the name for the new agent in 1937. One year later sulfapyridine, which possessed a wide spectrum of action, was marketed and became the preferred treatment of pneumococcal pneumonia. Although sulfapyridine was the sulfa drug of choice for a brief period, it was soon followed by sulfathiazole and then sulfadiazine.

During the second world war, Bayer was deeply involved in wartime research. While Domagk's work continued unhindered, he diligently attempted to persuade the military to employ the sulfa drugs more aggressively. He traveled through various parts of occupied Europe to apprise the German doctors of the benefits of using these drugs. The British army was cautious in employing the new agents before Dr. Leonard Colebrook convinced the military authorities to use them more extensively. By 1943, every German, British, and American soldier would carry a supply a sulfa drug or had ready access to it. The marked impact of sulfa drugs extended beyond war wounds to treating dysentery.

Domagk eventually shifted the focus of his work to the treatment of tuberculosis and cancer chemotherapy. Tuberculosis afflicted mainly the poor and was not considered particularly important for the army, so support for Domagk's work at Bayer began to wane. Nevertheless, his efforts to combat tuberculosis led to the development of semithiocarbazones, which are versatile compounds employed for treating antibacterial, antiviral, antifungal, and antimalarial disorders.

Sulfa drugs became generally available in the United States just five years prior to the Japanese attack on Pearl Harbor. Although supplies were restricted during the war for civilians, they were instrumental in reducing the morbidity and mortality of wound infections and gas gangrene in the military. The excitement created by the advent of these then novel drugs was to last for only another ten years, before they were superseded by penicillin and a plethora of other antibiotics. Bacterial resistance has limited the present day use of sulfa drugs; however they are still employed to treat urinary tract infections, ear infections, allergies, and skin disorders.

\section{Political aspects}

When the Nazis came into power, the leaders at IG Farben decided to concentrate on business and tried to remain apolitical. Although Horlein was sympathetic to the credos of Nazism and even joined the Nazi party [27], Domagk, on the other hand, did not support the policies of the Fascist regime. Although a patriotic German, he also had disdain for the edicts that prompted the exodus of colleagues from Germany and greatly diminished the quality of scientific research in Germany during the 1930's. In addition, his own experiences during World War I tempered his enthusiasm for the war effort and he became an avid supporter of the use of sulfa drugs to treat victims of the global conflict.

After the war, IG Farben was dismantled and the Bayer Company became a separate division. Directors of the conglomerate were tried by the Nuremberg War Crimes Tribunal for utilizing slave labor, confiscating property, and manufacturing poisonous gases [28]. After many years, it is still difficult to reconcile opposing perspectives on an organization which did so much to improve the human condition with the one that would forever be regarded as a scourge on mankind.

While Domagk continued to pursue his work, Heinrich Horlein was put on trial for complicity with the Nazi regime. However, it could not be proven that he had been aware of the use of poison gas and medical experiments in the concentration camps. After being acquitted of all charges, he returned to Bayer in 1949, given a pension, and served as director of the company's advisory board. He died in Wuppertal in 1954.

\section{The Nobel Prize}

Despite the wartime transgressions of the company, IG Farben spawned a new era in medicine, and Gerhard Domagk was awarded the Nobel Prize in 1939 "for the discovery of the antibacterial effects of prontosil" [29]. However, the German government forced him to decline the award as a consequence of moral stands taken by political dissidents such as Carl von Ossietzky, who had been awarded the Nobel Peace Prize. Domagk was even imprisoned for a short time. This edict delayed the formal presentation of the award until 1947. However, by this time the monetary award of the Prize had reverted to the Nobel Foundation [30].

While the Nobel Prize was given only to Domagk, one may argue that the award was deserved by others who contributed to the development of the sulfa drugs. They include Klarer, Mietzsch, Horlein, as well as members of the French group. Klarer's work was particularly valuable, as was the French team which discovered the active agent. However, the Prize was awarded to Domagk for the initial discovery of Prontosil, which provided the impetus for the discoveries of the many antibiotics that soon followed.

\section{Awards and Honorary Degrees}

Despite being rebuffed by the Nazi government, Domagk held many honorary doctorates from a number of European and South American Universities. He also was the recipient of the Paul Ehrlich Gold Medal and the Paul Ehrlich Prize; and served as a Foreign Member of the British Academy of Science, the Royal Society, and the Japanese Order of Merit of the Rising Sun [31].

\section{Epilogue}

Although the accomplishments of Gerhard Domagk were less celebrated than many other Nobelists, there has been no greater 
advancement in the annals of clinical medicine than the advent of antimicrobial chemotherapy. Prior to the work of Domagk, the concept that a bacterial infection could be cured by the systemic administration of a chemical substance was thought by most clinicians to be a fantasy and out of touch with reality. By demonstrating to other investigators that this goal could be achieved, Gerhard Domagk's contributions to the welfare of mankind earn him the highest accolades.

\section{References}

1. Chemical Heritage Foundation. Paul Ehrlich. August 2015. https://www. chemheritage.org/historical-profile/paul-ehrlich.

2. (1964) A complete bibliography of Gerhard Domagk can be found in: Colebrook L. Gerhard Domagk 1895-1964. Biogr Mem Fell Royal Soc 10: pg. 44-50.

3. Domagk G (1965) Biographical. The Nobel Prize in Physiology or Medicine 1939. Elsevier Publishing Company, Amsterdam, 1965. Gerhard Domagk. Chemical Heritage Foundation. We Tell the Story of Chemistry. Chemical Heritage Press; Philadelphia. 2003.

4. Cotton Simon (2011) Sulfanilamide (and its relatives). Molecule of the Month web page. July 2011. http://www.chm.bris.ac.uk/motm/sulfanilamide2/sulfanilamideh. htm. (retrieved May 30, 2017).

5. Domagk G (2003) Chemical Heritage Foundation. We Tell the Story of Chemistry. Chemical Heritage Press; Philadelphia

6. Colebrook L. Gerhard Domagk 1895-1964. Biogr Mem Fell Royal Soc 1964; 10: (Nov. 1964). pp. 38-40.

7. Hager T (2006) The Demon under the Microscope: From Battlefield Hospitals to Nazi Labs. Chapter 7. ISBN 1-4000-8214-5.

8. Gelmo P (1999) Sulphamides of p-aminobenzenesulphonic acid. Jf Prakt Chem 77: 369-382.

9. Azo dyes are defined as a class of synthetic organic compounds that contain nitrogen as the azo group (-N=N)-. http://www.britannica.com/science/azo-dye.

10. Horlein H (1909) Deutsches Reich Patentschrift. Number 226239.

11. Comroe, Julius H (1976) Missed Opportunities. Annu Rev Resp Diseases 114: (6) $1167-1168$.

12. Hager T (2006) The Demon under the Microscope: From Battlefield Hospitals to Nazi Labs. Chapter 6. ISBN 1-4000-8214-5.

13. Horlein H (1936) The chemotherapy of infectious diseases caused by protozoa and bacteria. Proc Roy Soc Med 23: 319-324.

14. Biographies. Gerhard Domagk. Bayer AG. https://www.bayer.com. (Last updated January 4, 1916. (Retrieved June 21, 2017).

15. Cotton Simon (2011) Sulfanilamide (and its relatives). Molecule of the Month web page. July 2011. http://www.chm.bris.ac.uk/motm/sulfanilamide2/sulfanilamideh. htm. (Retrieved May 30, 2017).

16. The Making of a Miracle Drug. Finding the first Antibiotic. Smells like Science. (Part 3 of a 4 part series about Scientific Discovery). 5/19/2017. http://smellslikescience. com/the-making-of-a-miracle-drug/ (retrieved May 31, 2017).

17. Domagk G (1935) Ein Beitrag zur Chemotherapie der bakteriellen Infektionen. Deutsche med Wchnschr 61:250-253. Experimental details of Domagk's work can also be found in: Horlein Professor H. The chemotherapy of infectious diseases caused by protozoa and bacteria. Section of Tropical Diseases and Parasitology. Proc. Royal Soc. Med. 1935; 29: pp. 319-324.

18. Horlein, Heinrich (1937) The development of chemotherapy for bacteriological diseases. Practitioner 139: 635-649.

19. Forbes GB (1972) A. Ashley Weech M.D. Amer J Dis of Children 124(6): 818-819.

20. Weech AA (1970) The guiding lamp of history. Amer Dis of Children 119(3): pg. 199.

21. Perrin L, Eleanor B (2017) The Clinical and Experimental Use of Sulfanilamide. Sulfapyridine and Allied Compounds. (1939). New York; The Macmillan Company. 318 pages. See also: Prontosil- from Wikipedia. May 2017.

22. Rubin RP (2007) Great Discoveries in Pharmacology. Pharmacol Rev 59: 308-314.

23. Hager T (2006) The Demon under the Microscope: From Battlefield Hospitals to Nazi Labs. 164-166. ISBN 1-4000-8214-5.

24. Fourneau E, Trefouel JT, Nitti F, Bovet D (1936) Chimiotherapie des infections streptococciques par les derives du p-aminophenylsulfamide. Compt Rend Soc de biol 122: 652-654.

25. Domagk G (1935) Eine neue Klasse von Desinfektionsmitteln. Deutch. Med. Wochenschrift. 61(7): 250-253. Ibid. Chemotherapie der bakteriellen Infektionen 61(21): 829-832.
26. Hager T (2006) The Demon under the Microscope: From Battlefield Hospitals to Nazi Labs. Chapter 12. ISBN 1-4000-8214-5.

27. Colebrook L, Kenny M (1936) Treatment of puerperal infections and experimental infection in mice, with prontosil. Lancet 16: 1279-1286.

28. Hager T (2006) The Demon under the Microscope: From Battlefield Hospitals to Nazi Labs. 180-181. ISBN 1-4000-8214-5.

29. Donohoe, Gabriel (2008) Nuremberg Trials: Big Pharma's Crimes Against Humanity. Natural News.com http://www.naturalnews,com/024534_europe health_WHO.hml.

30. Rubin RP (2007) A Brief History of Great Discoveries in Pharmacology. 59: pg. 318 .

31. Colebrook L. Gerhard Domagk 1895-1964. Biogr Mem Fell Royal Soc 1964. 10: (Nov. 1964). pg. 44. Gerhard Domagk- Biographical. The Nobel Prize in Physiology or Medicine 1939. Elsevier Publishing Company, Amsterdam, 1965.

\section{Citation:}

Ronald P. Rubin (2018) Gerhard Domagk (1895-1964) and the Origin of AntiBacterial Therapy. Internal Med Res Open J Volume 3(2): 1-6 